\title{
A COMPARATIVE STUDY BETWEEN DIAGNOSTIC NASAL ENDOSCOPY (DNE) AND CT PARANASAL SINUS IN CASES OF CHRONIC RHINOSINUSITIS
}

\author{
R. Manoj Kumar' ${ }^{1}$ S. Elangovan ${ }^{2}$
}

${ }^{1}$ Assistant Professor, Department of ENT, Dhanalakshmi Srinivasan Medical College, Perambalur.

2 Professor, Department of ENT, Dhanalakshmi Srinivasan Medical College, Perambalur.

ABSTRACT
BACKGROUND
The objective of the study was to elicit the correlation of CT paranasal sinus and diagnostic nasal endoscopy in cases of chronic
rhinosinusitis.
rhinosinusitis.

\section{MATERIALS AND METHODS}

It was a randomised prospective study which was a tertiary hospital based study. It included 100 diagnosed patients of chronic rhinosinusitis. DNE and CT PNS was done and all the selected cases and comparable parameters were compared.

\section{RESULTS}

On comparison, CT PNS was found to be better in many of the considered parameters when compared to DNE.

\section{DISCUSSION}

Variations in middle turbinate, pneumatisation of ethmoidal air cells, were better seen in CT as compared to nasal endoscopy. Accessory nasal ostia was only seen in DNE. In some cases, it was impossible to pass endoscope beyond a certain point due to the presence of gross pathology, there CT proved very helpful.

\section{CONCLUSION}

Nasal endoscopy was better for assessment of localised features like polyp, secretion, and colour of mucosa while CT gave a better idea of condition of paranasal sinus and the ostiomeatal complex. CT scan delineates the extent of disease, anatomical and pathological variations far better than DNE.

\section{KEYWORDS}

Sinusitis, DNE, CT PNS.

HOW TO CITE THIS ARTICLE: Kumar RM, Elangovan S. A comparative study between diagnostic nasal endoscopy (DNE) and CT paranasal sinus in cases of chronic rhinosinusitis. J. Evolution Med. Dent. Sci. 2016;5(93):6869-6871, D0I:10. $14260 /$ jemds/2016/1552

\section{BACKGROUND}

India is a country where almost $15 \%$ of the population is suffering from chronic rhinosinusitis, ${ }^{1}$ CT scan of paranasal sinuses and diagnostic nasal endoscopy [DNE] are the two commonly used investigative modalities for chronic rhinosinusitis. ${ }^{2,3}$

CT scan obviously is a radiological investigation and quite expensive for the patient. On the other hand, DNE is a simple outpatient procedure which can be done in a few minutes, with less than minimal risk to the patient.

CT scan of paranasal sinuses has become the gold standard investigation for preoperative evaluation of the patient. ${ }^{4}$ But only less than $10 \%$ of rhinosinusitis patients opt for surgical management, for whom CT scan can be mandatory.

The rest $90 \%$ of the patients are widely prescribed CT PNS as a part of routine evaluation of rhinosinusitis without a proper DNE.

Financial or Other, Competing Interest: None.

Submission 13-10-2016, Peer Review 09-11-2016,

Acceptance 14-11-2016, Published 21-11-2016.

Corresponding Author:

Dr. R. Manoj Kumar,

Reg. No. 80556, No. 11/125,

Ganapathy Nagar,

T. V. Koil, Srirangam,

Trichy-620006.

E-mail: manojbalaji9984@gmail.com

DOI: 10. 14260/jemds/2016/1552

(c) $($ ) $($ )
Since, the hidden areas like posterior ethmoidal, sphenoid sinus, etc can only be seen in CT PNS, ,5 findings that are visible both in DNE and CT PNS in common are compared. The aim of this study is to compare the comparable parameters of CT PNS and DNE evaluation, and if DNE is found to be better than or as effective as CT paranasal sinuses in evaluating cases of chronic rhinosinusitis, a cheaper and radiation free investigation (DNE) can more effectively be used for patient evaluation in future.

\section{MATERIALS AND METHODS}

Source of Data

Patients attending the ENT OPD with different nasal symptoms of sinonasal diseases at Dhanalakshmi Srinivasan Medical College, Perambalur.

\section{Methods of Collection of Data Inclusion Criteria}

Patients presenting with complaints like headache, nasal obstruction, such as symptoms difficult to diagnose by anterior rhinoscopy and posterior rhinoscopy, not responding to medical line of management based on clinical examination are the cases selected for CT PNS and DNE.

\section{Exclusion Criteria}

1. Children who do not co-operate for DNE and CT PNS.

2. Females in reproductive age group with suspected pregnancy. 
3. Patients with acute rhinosinusitis.

4. Patients with suspected sinonasal malignancies/ rhinosporidiosis/JNA/bleeding tendencies.

\section{Duration of Research Project}

i) Period which may be needed for collecting the data: 6 months.

ii) Period that may be required for analysing the data: 2 months.

iii) Total period required to complete the project: 8 months.

iv) What will be the date/month/year of termination of the Project, including follow-up duration- 31/05/2016.

v) Sample size: 100 .

vi) Study design: Prospective.

\section{Collection of Data}

- After a careful history and examination, informed consent was taken from all the study patients.

- $\quad$ Patients were clearly explained about the procedure of DNE and were advised not to sneeze or turn their head during the procedure. In case of any discomfort, they were advised to convey it orally, so that the scope can be withdrawn at any point of time during the procedure.

- $\quad$ Patients were made to lie on examination couch with $30^{\circ}$ head-up position and head tilted mildly towards the examiner who is standing in the right side of the patient.

- Both the nasal cavities are packed with cotton packs soaked in a solution of $4 \%$ Xylocaine and adrenaline (1 ampoule adrenaline in $30 \mathrm{~mL}$ of $4 \%$ Xylocaine) and left for 10 to 15 minutes.

- Using a $0^{0}$ Hopkins rod, endoscopic camera and halogen light source, diagnostic nasal endoscopy was performed in 3 passes, after removing the cotton packs.

- During the first pass, inferior turbinate, nasal cavity, septum and nasopharynx were examined. During the second pass, superior turbinate, sphenoethmoidal recess and sphenoid sinus ostium were visualised. During the third pass, middle meatus region including uncinate process, hiatus semilunaris, middle turbinate $(\&$ its variations), bulla ethmoidalis, presence of any discharge/polypoidal changes in middle meatus were noted.

- Fogging of endoscope during the procedure was prevented using Savlon solution.

- After the procedure, the findings were noted mainly under six topics, namely septal deviation, polyp/mucosal oedema, inferior turbinate, middle turbinate variations, enlarged bulla ethmoidalis and accessory ostium.

CT para nasal sinuses both coronal and axial $3 \mathrm{~mm}$ cuts were taken for all these patients and findings were noted under the same above-mentioned six topics.

Finally, these six parameters were compared and the results were compiled.

\section{RESULTS}

Of the total 100 patients taken for the study,

1. Septal deviation was appreciated better in CT PNS when compared to DNE by $18 \%$.

2. Polyps and mucosal oedema was appreciated better in DNE when compared to CT PNS by $15 \%$.
3. Inferior turbinate hypertrophy was appreciated better in CT PNS when compared to DNE by $12 \%$.

4. Middle turbinate variations were better appreciated by CT PNS when compared to DNE by $10 \%$.

5. Enlarged bulla ethmoidalis was appreciated better in CT PNS when compared to DNE by $7 \%$.

6. Accessory ostium was only appreciated in DNE.

\section{DISCUSSION}

Age

In the present study, maximum number of patients were in the age group 26-35 (approx 63\%) that is the second and the third decades.

Sex

Of the total 100 patients taken for study, 62 patients were male and 38 patients were females.

\section{Diagnostic Nasal Endoscopy vs. CT PNS Deviated Nasal Septum}

On nasal endoscopy, deviated nasal septum was noted in $65 \%$ of the patients and in CT PNS, it was noted in $82 \%$ of the patients. It was noted that significant gross deviated nasal septum was detected by both CT PNS and DNE whereas minimal insignificant deviated nasal septum was detected only in CT PNS7. Similarly, posterior deviations are better detected in CT PNS than with DNS especially in cases with hypertrophied inferior turbinates where passing the endoscope become difficult posteriorly.

\section{Polyp/Mucosal Oedema}

Mucosal oedema in the middle meatal region is one of the early signs of rhinosinusitis. ${ }^{8}$ Here only the polypoidal changes and mucosal oedema in the middle meatal region and nasal cavity are compared, since the polyps within the sinuses can only be visualised with CT PNS.

On nasal endoscopy, $38 \%$ of the patients were found to have nasal polyps/early polypoidal changes whereas only $23 \%$ of the patients were found to be diagnosed with CT PNS. The main reason for this superior diagnosing ability of nasal polyps by DNE is due to the possibility of applying suction, clearing the secretions and direct visualisation of the suspected region ${ }^{9}$ which is not possible with CT PNS where mucoid discharge (Which occurs in 20 to $30 \%$ of cases according to studies conducted by $\mathrm{K}$. Sinha et $\mathrm{al}^{4}$ ), mucosal oedema, early polyps will all give a similar picture which might be confusing for the radiologists. However, larger polyps are equally well diagnosed by these two modalities.

\section{Inferior Turbinates}

On nasal endoscopy, $58 \%$ of the patients were found to have hypertrophied inferior turbinate whereas $70 \%$ of patients were found to be reported as hypertrophied inferior turbinates with CT PNS. This is mainly due to over reporting of hypertrophied inferior turbinate where even a minor mucosal thickening is considered significant and reported.

\section{Middle Turbinate Variations}

Middle turbinate variations include hypertrophied middle turbinate, paradoxical middle turbinate, double turbinates, etc.

It was noted in $35 \%$ of the cases in DNE and $45 \%$ of the cases in CT PNS. 
That $10 \%$ difference is mainly noted in cases of gross deviated nasal septum which was blocking the view of the middle turbinate in that corresponding side.

\section{Ethmoidal Air Cells}

As far as ethmoidal air cells are concerned only bulla ethmoidalis can be visualised with DNE which also may not be visualised well in cases with concha bullosa or gross DNS. So, for visualising bulla ethmoidalis and other hidden ethmoidal air cells like Haller cell and Onodi cell, CT PNS is the investigating modality of choice beyond doubt.

In this study, enlarged bulla ethmoidalis overlapping the hiatus semilunaris was noted in $24 \%$ of cases with CT PNS and $18 \%$ of the cases with DNE.

\section{Accessory Ostium}

Accessory ostium was found in $36 \%$ of cases with DNE and it can never be detected in a CT PNS.

\section{Comparable Parameters between CT PNS and DNE}

\begin{tabular}{|c|c|c|}
\hline Parameter & DNE & CT PNS \\
\hline Septal deviation & $65 \%$ & $82 \%$ \\
\hline Polyp/mucosal oedema & $38 \%$ & $23 \%$ \\
\hline Inferior turbinate & $58 \%$ & $70 \%$ \\
\hline Middle turbinate Variations & $35 \%$ & $45 \%$ \\
\hline Enlarged bulla ethmoidalis & $18 \%$ & $24 \%$ \\
\hline Accessory ostium & $36 \%$ & $0 \%$ \\
\hline \multicolumn{2}{|c}{ Table 1 } \\
\hline
\end{tabular}

\section{CONCLUSION}

Previously there were studies considering DNE as gold standard for diagnosing chronic rhinosinusitis ${ }^{10}$ and studies considering CT PNS as the gold standard for diagnosing chronic rhinosinusitis. ${ }^{11,12}$

Even though, at present, CT paranasal sinus has become the gold standard investigation for severe chronic rhinosinusitis patients planned for surgical intervention, the importance of a proper diagnostic nasal endoscopy must never be under emphasised. When a cheap simple outpatient procedure like DNE can give information which is as good as or even (for some parameters) better than CT PNS, it must be properly utilised in the diagnosis of chronic rhinosinusitis.
This will significantly reduce the need for CT PNS and henceforth the economic burden and radiation exposure caused by it.

\section{REFERENCES}

1. Sood VP. Chronic rhinosinusitis. ECAB. India: Elsevier 2012.

2. Stamberger H. An endoscopic study of tubal function and the diseased ethmoid sinus. Arch Otolaryngol 1986;243(4):254-9.

3. Kirtane MV. Functional endoscopic sinus surgery (A preliminary study). Indian Journal of Otolaryngology 1991;43(3):126-9.

4. Sinha DK. Nasal and sinus endoscopy in opaque maxillary antrum. Indian Journal of Otolaryngology and Head and Neck Surgery 1993;45(3):145-6.

5. Dua K, Chopra H, Khurana AS, et al. CT scan variations in chronic sinusitis. Indian Journal Radiology Image 2005;15(3):315-20.

6. Saxena R, Kanodia V, Srivastava M. Role of CT paranasal sinuses and diagnostic nasal endoscopy in the treatment modification of chronic rhinosinusitis. Gujarat Journal of Otorhinolaryngology and Head \& Neck Surgery 2010;7(1):7.

7. Shahizion AM, Suraya A, Rozman Z, et al. Correlation of computed tomography and nasal endoscopic findings in chronic rhino sinusitis. Med Journal Malaysia 2008;63:3.

8. Bolger WE, Parsons DS, Butzin CA. Paranasal sinus bony anatomic variation and mucosal abnormalities: CT analysis for endoscopic sinus surgery. The Laryngoscope 1991;101(1 pt 1):56-64.

9. Schlosser RJ, Kennedy DW. Nasal endoscopy. In: Scott Brown's otolaryngology-head and neck surgery. $17^{\text {th }}$ edn. London: Edward Arnold 2008:1344-54.

10. Shelkar R, Vedi G, Ekhar V, et al. Role of nasal endoscopy in sinonasal disease. International Journal of Scientific Study 2014;2(1):06-10.

11. Geminiani RJ, Vitale RF, Mazer $A B$, et al. Comparison between computed tomography and nasal endoscopy in diagnosis of chronic rhinosinusitis. International Archives of Otolaryngology 2007;11:4.

12. Bhattacharyya N, Lee LN. Evaluating the diagnosis of chronic rhinosinusitis based on clinical guidelines and endoscopy. Otolaryngol Head Neck Surgery 2010;143(1):147-51. 